\title{
Model based Design of an Electrical Hybrid Vehicle with Energy Management
}

\author{
Guenidi Sif Eddine \\ Ecole Nationale Polytechnique \\ 10, ave Hassen Badi, BP. 182 \\ El-Harrach Algiers Algeria
}

\author{
Mohamed Tadjine \\ Ecole Nationale Polytechnique \\ 10, ave Hassen Badi, BP. 182 \\ El-Harrach Algiers Algeria
}

\author{
Mohamed. S Boucherit \\ Ecole Nationale Polytechnique \\ 10, ave Hassen Badi, BP. 182 \\ El-Harrach Algiers Algeria
}

\begin{abstract}
This work is devoted to the modeling and simulation of hybrid electric vehicles with two sources of energy: a combustion engine and an electric motor.
\end{abstract}

The Series / Parallel architecture is adopted for modeling, and each part of the traction is modeled separately.

The constructed vehicle's model for simulation consists of assembling different blocks by connecting components in a structured manner with respect of the physical causality.

For the control of the powertrain, a strategy is developed, whose role is to choose at every moment the best power distribution between the different energy sources in order to minimize fuel consumption and pollutants emissions.

\section{Keywords}

Hybrid electric vehicle, Simulation, Modeling, Control strategy, Energy Management

\section{INTRODUCTION}

In this paper, we examine a model of hybrid-electric vehicle type series / parallel under Matlab/Simulink [2], using the positions of the pedal (acceleration / deceleration) deducted from the driving cycle as main input signal.

The simulation illustrates the flow of energy and its distribution under different modes of traction of the hybrid vehicle.

All the traction components are modeled and assembled together to create an energy model (Figure 1) capable of simulating the hybrid behavior, that combines the different energy sources efficiently and optimally by using a control system to share the power with a positive impact on the fuel economy aiming to reduce polluting emissions to the atmosphere

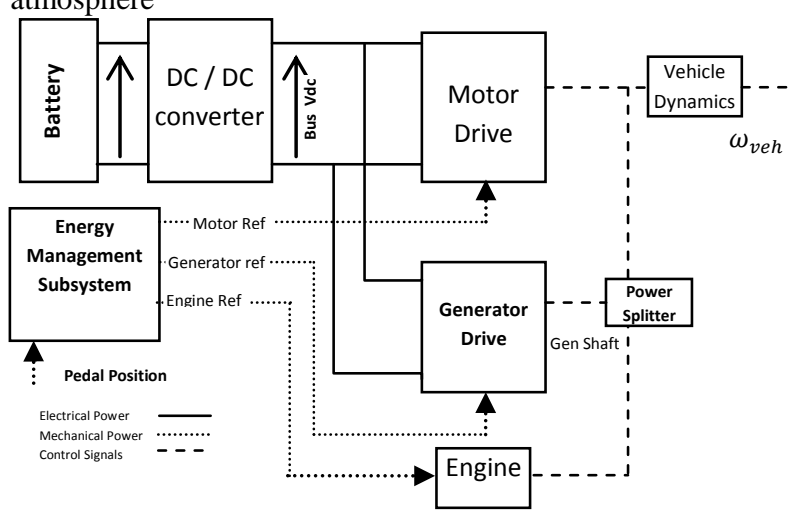

Figure 1: Overview of the simulation model of the hybrid vehicle

\section{SIMULATION MODEL}

In this paper, we examine a model of hybrid-electric vehicle type series / parallel under Matlab/Simulink [2], using the positions of the pedal (acceleration / deceleration) deducted from the driving cycle as main input signal.

The simulation illustrates the flow of energy and its distribution under different modes of traction of the hybrid vehicle.

All the traction components are modeled and assembled together to create an energy model (Figure 1) capable of simulating the hybrid behavior, that combines the different energy sources efficiently and optimally by using a control system to share the power with a positive impact on the fuel

\subsection{Driving Cycle}

As part of this study, a driving cycle expresses the vehicle speed versus time. It measures the consumption and / or the emissions of pollutants in identical driving conditions for all vehicles.

For the simulation purposes and to reproduce a road trip with different driving conditions, the New European Driving Cycle (NEDC) is used. (Figure 2)

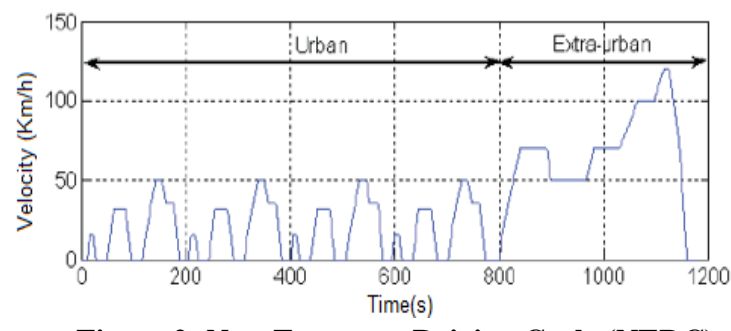

Figure 2: New European Driving Cycle (NEDC)

\subsection{Vehicle Dynamics}

The movement behavior of a vehicle along its moving direction is completely determined by all the forces acting on it in this direction. (Figure 3) shows the forces acting on a vehicle moving up a grade.

The tractive effort, $\mathrm{Ft}$, in the contact area between the tires of the driven wheels and the road surface propels the vehicle forward. It is produced by the power plant torque and transferred through transmission and final drive to the drive wheels while the vehicle is moving, there is resistance that tries to stop its movement. The resistance usually includes tire rolling resistance, aerodynamic drag, and uphill resistance 


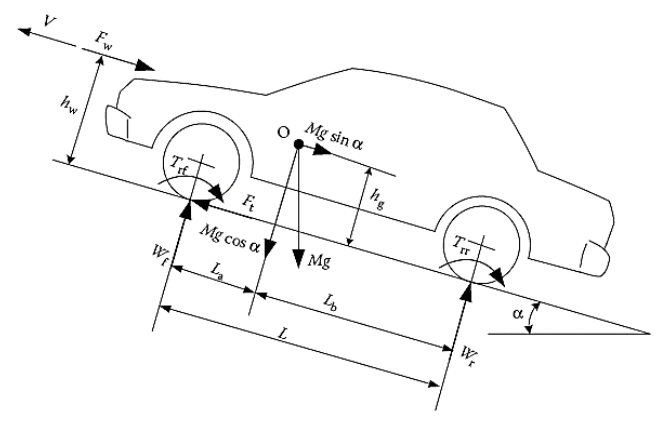

Figure 3: Forces acting on a vehicle climbing a grade[3] According to Newton's second law, vehicle acceleration can be written as:

$$
\frac{d V}{d t}=\frac{\sum F_{t}-\sum F_{r}}{\delta \cdot M}
$$

where $\mathrm{V}$ is the speed of the vehicle, , $\sum \mathrm{Ft}$ is the total tractive effort of the vehicle, $\sum \mathrm{Fr}$ is the total resistance, $\mathrm{M}$ is the total mass of the vehicle, and $\delta$ is the mass factor that equivalently converts the rotational inertias of rotating components into translational mass.

The dynamic equation of vehicle motion along the longitudinal direction is expressed by :

$$
M \frac{d V}{d t}=\left(F_{t f}+F_{t r}\right)-F_{r f}+F_{r r}+F_{g}+F_{w}
$$

(2)

Where $\frac{d V}{d t}$ is the linear acceleration of the vehicle along the longitudinal direction and $\mathrm{M}$ is the vehicle mass.

$F_{r f}, F_{r r}$ : Rolling resistance of the front and rear tires

$F_{t f}, F_{t r}$ : Tractive effort of the front and rear tires.

$F_{w} \quad$ : Aerodynamic drag.

$F_{g} \quad$ : Climbing resistance,

This dynamic model is a simplified one that ignores the forces of rolling and pitching. The vehicle is modeled as a mass in movement subject to the driving force $\mathrm{Ft}$ developed by the powertrain and various efforts related to the environment.

By applying the fundamental principle of the dynamic on equation 2, we can deduce the velocity $\mathrm{V}$ of the vehicle. [3].

\subsection{The Engine}

An internal combustion engine converts the chemical energy into mechanical energy. The most used ICE's are gasoline and diesel engines.

The engine model uses a programmed relationship between torque and speed, modulated by the throttle signal

At the output, a vector containing the torque and the engine speed is available. This block is a very simple model that does not include the dynamics of combustion involving no friction and the associated losses.

Figure 4 shows: Torque / Speed $(\mathrm{T}=\mathrm{f}(\mathrm{w}))$ and Power / Speed of the engine $(\mathrm{P}=\mathrm{f}(\mathrm{w}))$ [4]
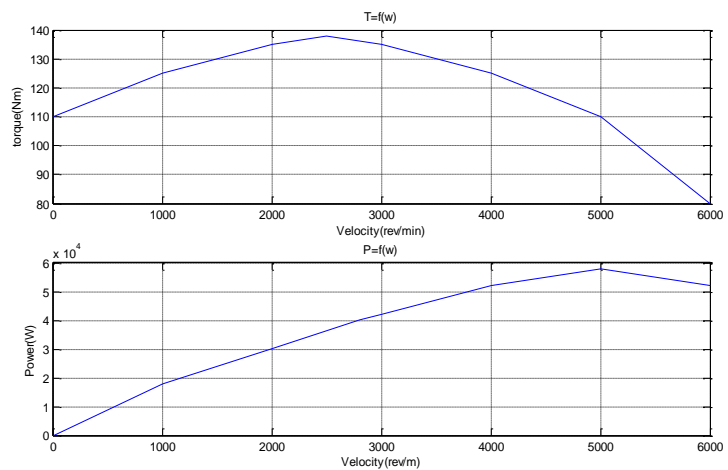

Figure 4: Torque / Speed and power / speed of the ICE

\subsection{Planetary gear train}

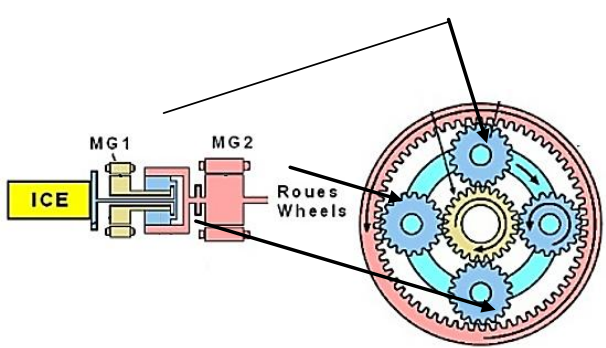

Figure 5: Planetary gear 
The hybrid electrical vehicle adds up three sources of energy, ICE and two electrical sources, it involves the use of a power splitter to make full performance of each one of them.

The type of power splitter used, is a planetary gear (Figure 05). The planetary gear represents a set of carrier, ring, planet, and sun gear wheels, it can be constructed from sun-planet and ring-planet gears. The ring and sun co-rotate with a fixed gear ratio.

The engine is connected to the ring gear, the electric motor is connected to the sun gear. [3]

\subsection{Battery}

We present here one of the technological ways to have power source on board. These are the batteries used in all the current hybrid vehicles.

The type of batteries chosen is nickel-metal hydride batteries, they have superior density and volumetric energy performance, much higher than the technology based on lead or cadmium. This type of battery in his traction version, mainly equipped Japanese vehicle companies like Toyota Prius.

The used battery model [5] is simply a controlled voltage source in series with an internal resistance, but it reproduces exactly the curves of charge/discharge of most types of batteries, it is a dynamic customizable model.

The following schematic shows the equivalent circuit of the dynamic model:

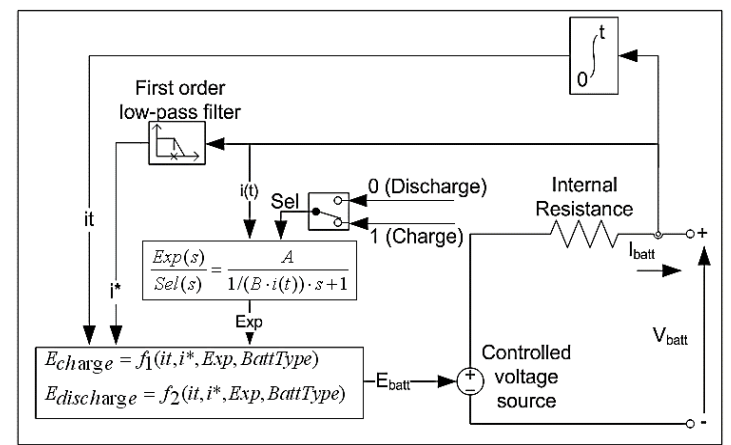

Figure 6: Generic dynamic battery model [5]

\begin{tabular}{|c|c|c|}
\hline $\begin{array}{l}\text { Battery } \\
\text { Type }\end{array}$ & State & Mathematical model \\
\hline \multirow{2}{*}{$\begin{array}{l}\text { Nickel- } \\
\text { Metal- } \\
\text { Hydrid }\end{array}$} & $\begin{array}{c}\left(\boldsymbol{i}^{*}<0\right) \\
\text { Charge }\end{array}$ & $\begin{array}{l}f_{2}\left(i t, i^{*}, i, \operatorname{Exp}\right)=E_{0}-K \cdot \frac{Q}{|i t|+0.1 . Q} \cdot i^{*}-K \cdot \frac{Q}{Q-i t} \cdot i t \\
+L^{-1}\left(\frac{\operatorname{Exp}(s)}{\operatorname{Exp}(s)} \cdot \frac{1}{s}\right)\end{array}$ \\
\hline & $\begin{array}{r}\left(\boldsymbol{i}^{*}>0\right) \\
\text { Discharge }\end{array}$ & $\begin{array}{l}f_{I}\left(i t, i^{*}, i, \operatorname{Exp}\right)=E_{0^{-}}-K \cdot \frac{Q}{Q-i t} \cdot i^{*}-K \cdot \frac{Q}{Q-i t} \cdot i t^{+} \\
L^{-1}\left(\frac{\operatorname{Exp}(s)}{\operatorname{Sel}(s)} \cdot 0\right)\end{array}$ \\
\hline
\end{tabular}

TABLE I : Charge / Discharge mathematical models for NiMh battery

\begin{tabular}{|l|l|}
\hline $\mathrm{E}_{\text {Batt }}=$ Nonlinear voltage $(\mathrm{V})$ & $\begin{array}{l}\mathrm{i}^{*}=\text { Low frequency current } \\
\text { dynamics }(\mathrm{A})\end{array}$ \\
\hline $\mathrm{E}_{0}=$ Constant voltage $(\mathrm{V})$ & $\mathrm{i}=$ Battery current $(\mathrm{A})$ \\
\hline Exp(s) = Exponential zone dynamics $(\mathrm{V})$ & it = Extracted capacity $(\mathrm{Ah})$ \\
\hline
\end{tabular}

\begin{tabular}{|l|l|}
\hline Sel $(\mathrm{s})=0$ during battery discharge, & $\begin{array}{l}\mathrm{Q}=\text { Maximum battery capacity } \\
(\mathrm{Ah})\end{array}$ \\
\hline Sel(s) $=1$ during battery charging. & $\mathrm{A}=$ Exponential voltage $(\mathrm{V})$ \\
\hline $\mathrm{K}=$ Polarization constant $(\mathrm{Ah}-1)$ & $\mathrm{B}=$ Exponential capacity $(\mathrm{Ah})-1$ \\
\hline
\end{tabular}

\subsection{Converters}

Most hybrid vehicles are facing compatibility issues of energy sources, especially between DC's and AC's, and sometimes within the same category we can find incompatibilities between the voltages sources and receivers.

This problem implies the presence on board of the hybrid vehicles of electronic converters whose role is to remove operating inconsistencies.

Three types of conversions are used in the hybrid vehicle electric traction part:

\section{AC / DC converter (rectifier)}

A rectifier is used at the output of the generator for converting the three-phase AC voltage into DC voltage.

\section{DC / AC (UPS)}

An inverter is used to convert direct current into alternating current to supply the three-phase motor.

\section{A DC / DC converter (chopper)}

The hybrid vehicle has a $(20 \mathrm{~kW})$ battery hence the need for a DC / DC converter to help increase the voltage from $202 \mathrm{~V}$ to $500 \mathrm{~V}$. The power input/output of the converter is $20 \mathrm{~kW}$. The DC bus voltage across the capacitor is regulated at 500V. [6].

All used converters are bidirectional to allow the current to pass in both directions along the operating mode (traction or braking).

\subsection{Electrical Motors}

Doing the best choice of the electric powertrain components in a hybrid vehicle is a key element for a successful association between the ICE and electrical.

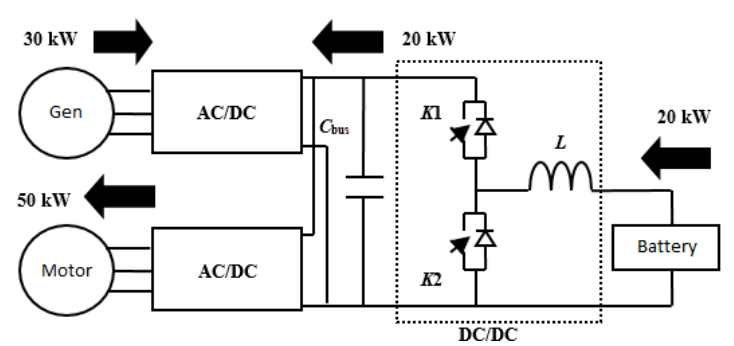

Figure 7: The electrical traction system inside HEV. [4] 
The permanent magnet synchronous motor (PMSM) appears in more than a way that is the most suitable for automotive traction thanks to its technical performance and particularly its compactness and efficiency.

The modeling of PMSM is through a state space representation of the second order, using the Park transformation. This representation is necessary because the inputs and outputs of the model of the synchronous machine are expressed in reference frame $a, b, c$.

The Park transformation, converts voltages and currents in each coil from the reference frame a, b, c into two components in the reference frame d,q,O.

The electrical and mechanical equations of the synchronous machine are as following:

$$
\left\{\begin{array}{c}
\frac{d}{d t} I_{d s}=\frac{1}{L_{d s}}\left(V_{d s}-R_{s} I_{d s}++\omega L_{d s} I_{d s}\right) \\
\frac{d}{d t} I_{q s}=\frac{1}{L_{q s}}\left(V_{q s}-R_{s} I_{q s}-L_{d s} \omega I_{d s}-\omega \varphi_{f}\right) \\
C e=\frac{3}{2} p\left[(L d s-L q s) I d s I q s+\varphi_{f} I q s\right] \\
C_{e}-C_{r}-f \Omega=J \frac{d \Omega}{d t}
\end{array}\right.
$$

As shown in (Figure 7) the PMSM (Motor) is connected to DC/AC convertor which allows for the control of motor torque, and adjusting the speed of the vehicle in both traction \& braking mode.

The DC / AC conversion can be achieved in many ways, but the requirements and characteristics of the hybrid vehicles with the rationalization of industrial solutions, led to a focus on the inverter structure with six bidirectional switches, formed by the association an IGBT, a mounted antiparallel diode, and will be controlled by PWM (Pulse Width Modulation) [7].

This type of installation will allow associating a voltage source (battery type) and a power source (asynchronous motor, synchronous motor coil, a permanent magnet or variable reluctance).

The inverter is controlled by (PMW) technique .It consist is to impose on the motor terminals a chopped voltages at a fixed frequency.

This type of installation will allow associating a voltage source (battery type) and a power source (asynchronous motor, synchronous motor coil, a permanent magnet or variable reluctance).

The inverter is controlled by (PMW) technique .It consist is to impose on the motor terminals a chopped voltages at a fixed frequency.

\subsection{Energy management system}

The energy management system presented (Figure 8) uses a simple algorithm based on a threshold logic, its goal is to develop according to the position of the vehicle's pedal and speed, the control of the entire powertrain whose role is to choose at every moment the best distribution of power between different energy sources in a manner to minimize fuel consumption and pollutant emissions.

Stateflow ${ }^{\circledR}$ is used to illustrate the different operating modes of the hybrid powertrain and the transition of an energy source to another.

Four operating modes are possible:
1. Starting

2. Acceleration

3. Cruise

4. Braking

$\square$ Starting

Starting the vehicle is fed by the electric motor, the idea is to have an all-electric mode and to keep the engine off.

\section{$\square$ Acceleration}

During a high acceleration demand the electric motor delivers its maximum power, he's mainly fed by the battery and the generator which is driven by the engine.

The engine works in his optimal performance area because when the torque demand is strong, the engine delivers its maximum power.

\section{$\square$ Cruise Mode}

In the cruise mode the planetary gear distributes the power generated by the ICE, it leads directly to the wheels and the generator, which in turn provides the necessary power to run the electric motor, while assisting in the vehicle traction too.

\section{Braking Mode}

During the phases of braking or deceleration of the vehicle, the electric motor operates as a generator and regenerates the kinetic energy from braking to recharge the battery.

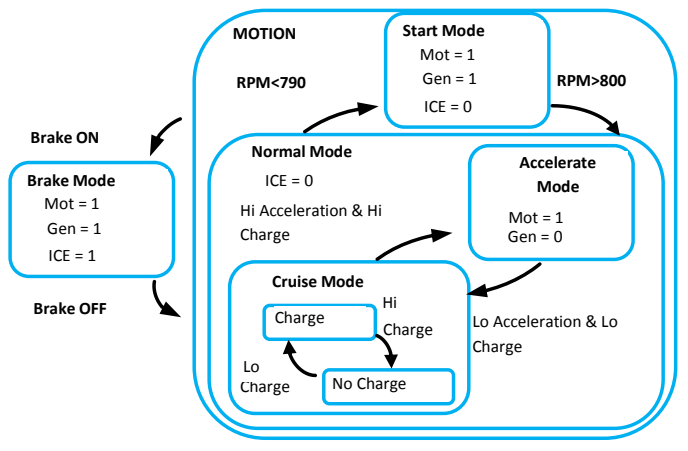

Figure 8: Mode logic modeled with Stateflow ${ }^{\circledR}[8]$ 


\section{SIMULATION AND RESULTS}

The results of these simulations [9] are made with the driving cycle (NEDC) (Figure 02) using motors/engine parameters of the Toyota Prius [6].

According to the optimal torque distribution (Figure 10) we can find the main features of the hybrid vehicle.

When the vehicle is stopped, the engine is automatically switched off. The electric motor operates to start the vehicle to a certain speed then the ICE turns to ensure the traction and

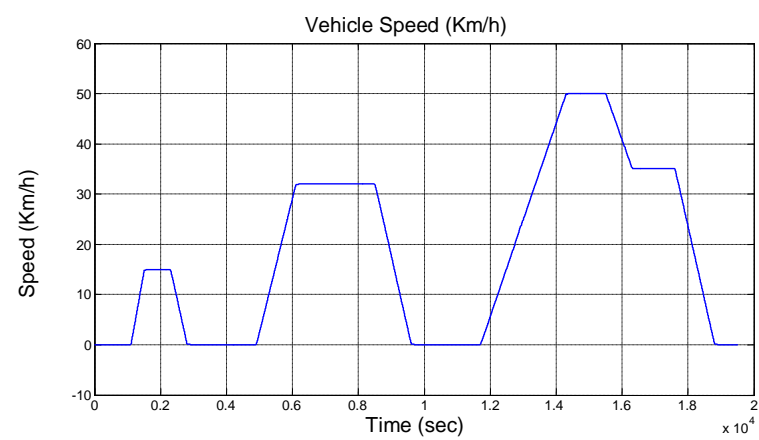

Figure 09: Vehicle's Speed

simultaneously charge the battery using the electric motor which functions in generator mode.

At a constant speed of the vehicle (Figure 09) (when it is less than $50 \mathrm{~km} / \mathrm{h}$ ), the traction is purely electric. All the decelerations of the vehicle are provided by the electric motor fed by recovery of the braking energy.

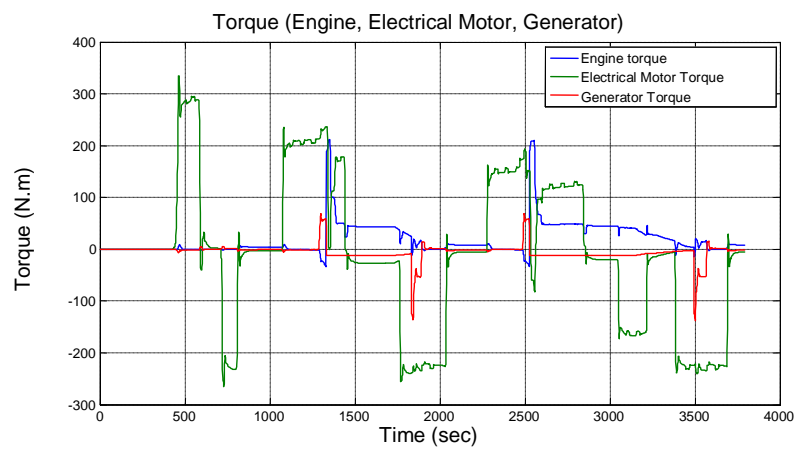

Figure 10: Motors/Engine Torque

The states of the vehicle's electrical motors and engine confirm the result of the simulation, the electric motor (Figure 11) displays a continuous contribution throughout the driving cycle, but the state of the engine (Figure 12) shows only a solicitation during high power applications such as acceleration. The generator (Figure 13) is activated when the engine is off to power the electric motor, and it instantly turns off when the engine starts and then restarts to recharge the battery. Note that the addition of the electric motors significantly reduces the use of the ICE and can even have an all-electric mode.

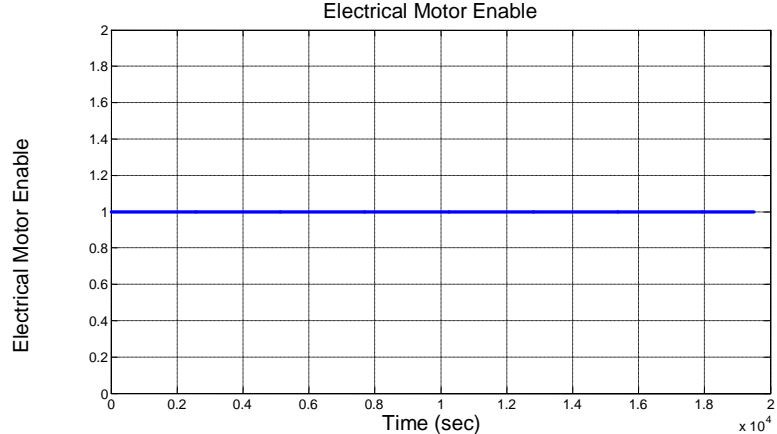

Figure 11: State of the Electrical Motor

The allure of the speed delivered by the driver via the accelerator pedal (Figure 14) is the same that illustrated by the ICE torque (Figure 15).

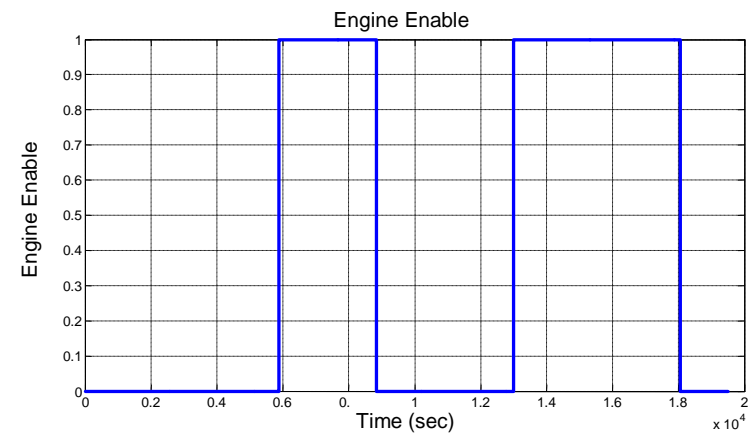

Figure 12: State of the Engine

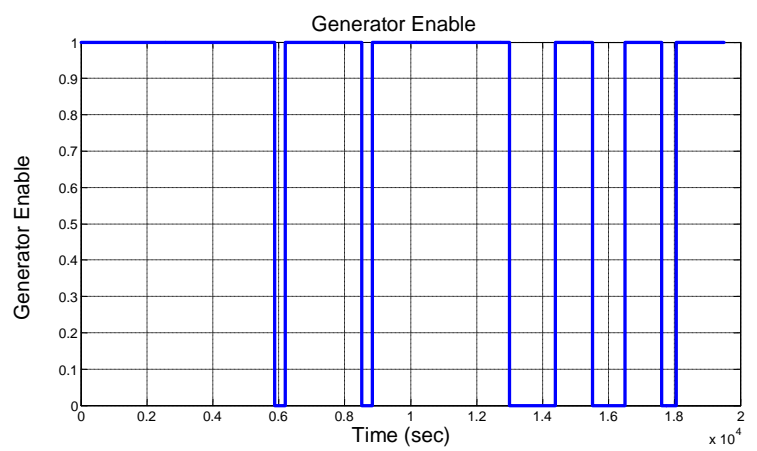

Figure 13: State of the generator

From the position of the accelerator pedal and the speed of the vehicle (Figure 09), the management system determines the optimum speed of the ICE and the target opening of the throttle valve.

The all-electric mode was simulated; all electric components are activated when the engine is off, the intent of keeping it off, is largely due to its ineffectiveness at low speed. 
With a limited storage device (Battery), the electrical motors were activated at low speed and low power conditions.

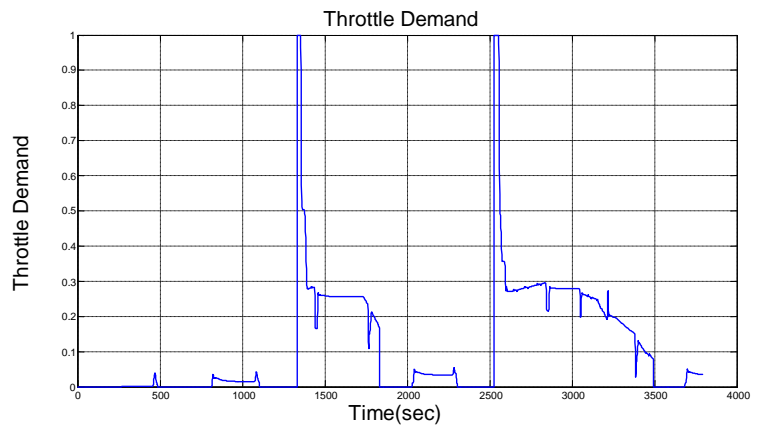

Figure 14: Throttle Demand

The state of charge of the battery (Soc \%) is the history of the battery along the used driving cycle.

The first Soc (Figure 16) was $100 \%$. The operating range is between $100 \%$ and $95 \%$.

The downward trend of the curve reflects the nature of discharge during the short period of simulation. Fluctuating Soc was caused by the battery being fed by the regenerative braking.

Due to the operating limit of the battery at a low charge level, the vehicle reaches a point where the ICE should start;

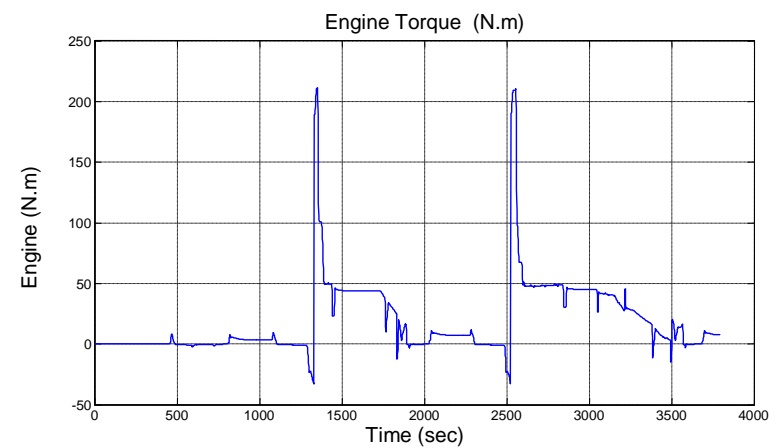

Figure 15: Engine Torque

Therefore, the time of the all-electric mode in the driving cycle was 60 seconds.

Unless the capacity of the battery is increased, the duration of all electric modes depend always on the state of charge and there is no specific time or range for this.

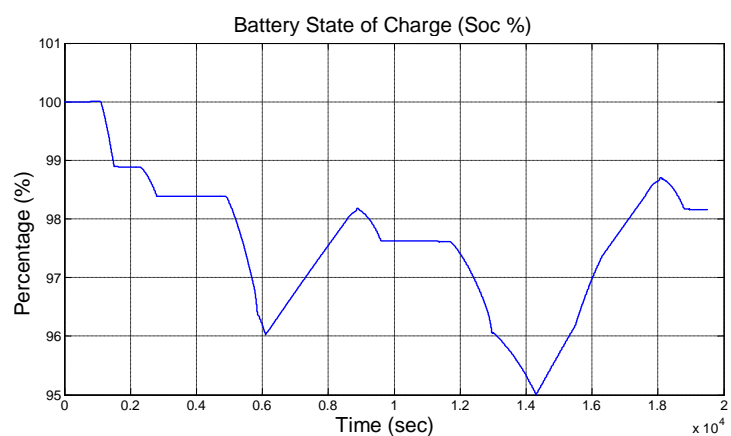

Figure 16: State of charge (Soc) of the battery

The DC bus voltage of the electrical system is regulated at $500 \mathrm{~V}$ (Figure 17), thus having a lower current (and therefore less loss) for the same required power. Bus voltage increase/decrease during periods of acceleration and regenerative braking.

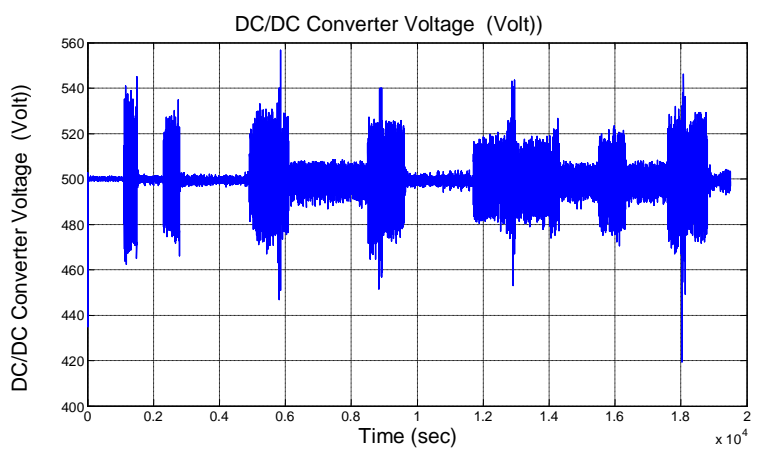

Figure 17: DC/DC Converter Voltage

The Input/output battery voltage (Figure 18) is maintained around $220 \mathrm{~V}$ during acceleration phases, the voltage falls below $220 \mathrm{~V}$ to feed the motor and during deceleration phases, the battery recharge by recovering braking energy.

The shape of the speed ( RPM) of the motor (Figure 19) is identical to the vehicle's speed ( Figure 12) this is due to allelectric mode that dominates the traction of the vehicle.

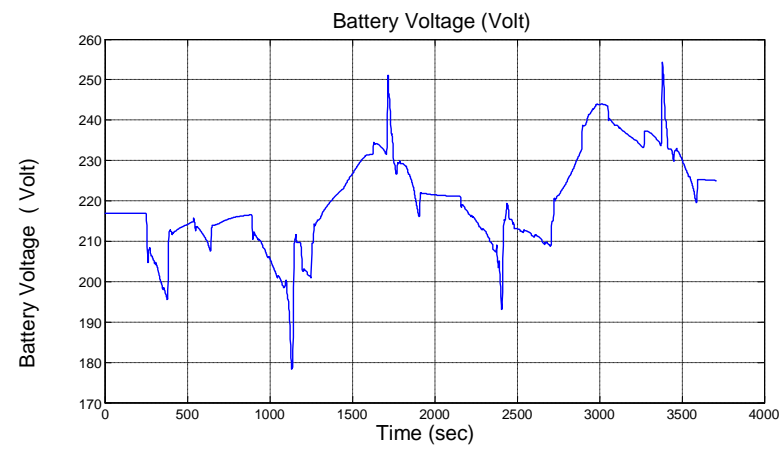

Figure 18: Battery Voltage 
The shape of the speed (RPM) of the generator (Figure 20) is identical to the speed of the engine (Figure 21) that is explained by the combined architecture used for the hybrid vehicle, where the generator is driven by the engine

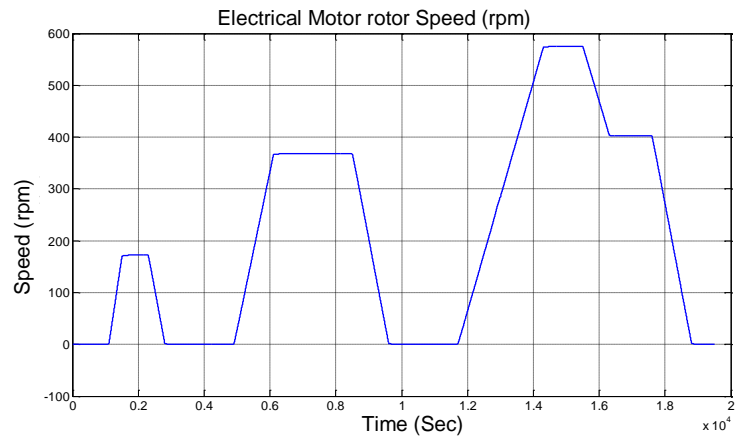

Figure 19: Rotor speed (rpm) of the electric motor

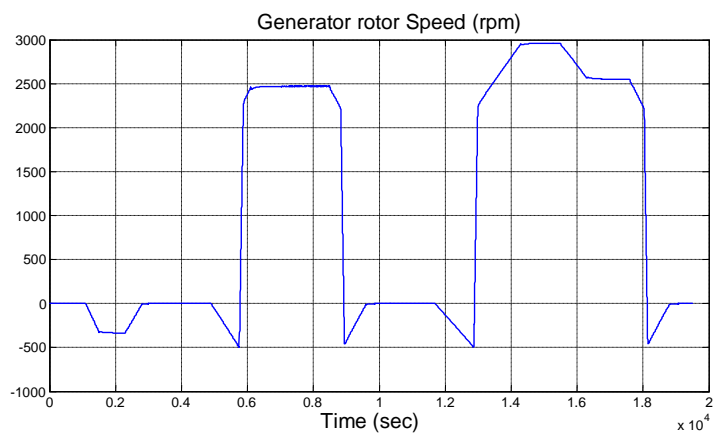

Figure 20: Rotor speed (rpm) of the generator

The control strategy selects the best distribution of power between the electric motor generator and battery. This strategy has helped to keep the electric motor still supplied without depleting the battery and allow it to recharge in this deceleration is mainly used to use the engine to the best of its performance and reduce emissions of carbon oxides and even the remove including an all-electric start .

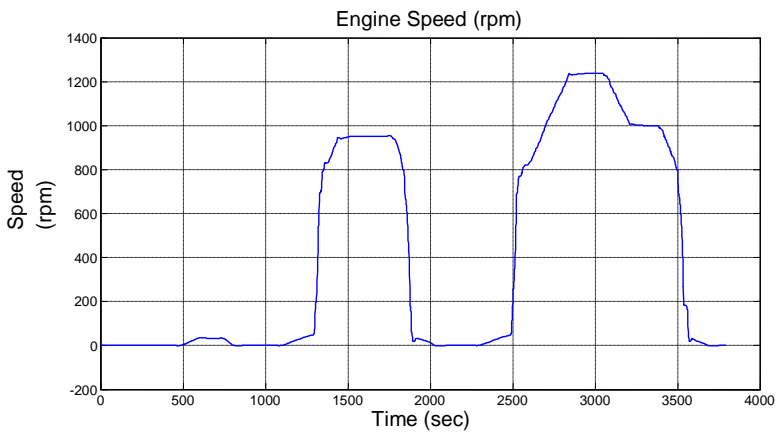

Figure 21: Rotor speed (rpm) of the generator

\section{CONCLUSION}

The purpose of this paper is the modeling, the simulation and the control of a hybrid electric vehicle, the model is designed to allow the study of the vehicle's performance facing the additional source of energy.

The Series / Parallel architecture and the control strategy chosen have a positive impact on the power management and the fuel consumption, therefore below $50 \mathrm{~km} / \mathrm{h}$, the vehicle is able to run in all-electric mode by keeping the engine off, above this speed, the hybrid control strategy can drive the vehicle using both electrical motors and the engine under duress the state of charge of the battery.

To clear this problem, the regenerative braking energy is recovered with the assistance of the generator which provides electrical energy from converting the mechanical power supplied by the engine.

The simulations under Simulink / Matlab show a stable vehicle following his driving cycle, the choice of the components and technological advances in power electronics facilitated the integration of a clean energy within the traditional vehicles, we indicated in this article, the importance of energy management because the availability of two types of energy on the vehicle, quires efficient sharing which serves to drive without constraints.

Left to say that the important observation throughout this work is that a bad energy management strategy leads to a hybrid electric vehicle that pollutes more than the conventional one, it forces us to double our efforts to design vehicles capable of reaching the purpose "zero emissions."

\section{REFERENCES}

[1] Lhomme Walter November 2007 PHD: Energy Management of HEV based on Energy Macroscopic Representation

[2] MATLAB Simulink Software," Hybrid Electric Vehicle model" Version 2011a.

[3] Ali Emadi, Yimin Gao and Mehrdad Ehsani 2010 .Modern Electric, Hybrid Electric, and Fuel Cel Vehicles Second Edition

[4] Bailly, Guillaume 2006. Multi-Domain Simulation of a Hybrid Electric Powertrain Using Matlab/Simulink, Master Dissertation, École de technologie supérieure Canada

[5] Oliver.,T 2009 Olivier Tremblay Louis-A.Dessaint Experimental Validation of a Battery Dynamic Model for EV Application Electrical Engineering Dep, Ecole de Technologie Superieure Canada.2009

[6] Staunton. R 2006 Staunton (r. h.), Ayers (c. w.), Chiasson (j. n.), Burres s (b. a.),Marlino (l. d.). Evaluation of 2004 Toyota Prius Hybrid Electric Drive System.- Technical Report Oak Ridge National Laboratory (ORNL). - May 2006, no. ORNL/ TM2006/423.

[7] Nouh Aiman. 2008, Contribution for the development of a Simulator for Electric Vehicles, PHD University of Franche Comté France.

[8] Model-Based Design for Hybrid Electric Vehicle Systems ,Saurabh Mahapatra, Tom Egel, Raahul Hassan, Rohit Shenoy, Michael Carone ,The MathWorks, Inc.2008.

[9] Guenidi Sif Eddine. Modeling, Control and Energy Management of a HEV, National Polytechnic School of Algiers.2011. 